\title{
INDUSTRIALIZAÇÁO DA EDUCAÇÃo, Edtech e Prática Docente
}

\author{
INDUSTRIALIZATION OF EDUCATION, EDTECH AND \\ Teaching ACTIVITY
}

Octavio Ribeiro de Mendonça Neto

Doutor em Contabilidade e Atuária pela Universidade de São Paulo. Professor do Programa de Pós-Graduação em Ciências Contábeis da Universidade Presbiteriana Mackenzie. São Paulo - SP octavio.mendonca@uol.com.br

Almir Martins Vieira Doutor em Educação pela Universidade Estadual Paulista. Professor do Programa de Pós-Graduação em Educação da Universidade Metodista de São Paulo. São Bernardo do Campo - SP almir.vieira@gmail.com

Maria Thereza Pompa Antunes

Doutora em Controladoria e Contabilidade pela Universidade de São Paulo. Coordenadora do Mestrado Profissional em Controladoria e Finanças da Fundação Instituto de Pesquisas Contábeis, Atuariais e Financeiras. São Paulo - SP - Brasil.

teantunes@uol.com.br

Resumo: Este trabalho tem por objetivo propor uma reflexão sobre o processo de industrialização da educaçáo nos tempos atuais, levando em conta a presença da educational technology (Edtech) como componente do cotidiano acadêmico-administrativo. Assumindo como elemento central a industrialização da educação, o texto se apresenta na forma de ensaio teórico, colocando em debate argumentos de pensadores que se posicionam a favor ou contra essa industrialização. A obra Industrialiser l'education: anthologie commentée (1913-2012), organizada por Pierre Moeglin (2016), assume papel central neste artigo. Primeiramente, são apresentados indicadores do processo de industrialização mencionado, além de princípios de cunho ideológico. O papel da Edtech também é tratado, inclusive com projeçóes e estimativas de abrangência em termos de valor de mercado, além do aspecto da educação a distância (EAD), cenário no qual a Edtech assume papel crucial. No tocante à pratica docente, esse processo de industrialização da educação exige das instituiçóes de ensino modelos de gestão baseados na calculabilidade e na busca pela eficiência, introduzindo no ambiente educacional sistemas de informaçáo que, ao mesmo tempo, facilitam atividades dos docentes, mas servem também para vigiar, adestrar (dressage), controlar e avaliar seu desempenho.

Palavras-Chave: Edtech. Gestão da Educação. Industrialização da Educação. Prática Docente.

Aвsтract: This paper presents a discussion about the industrialization of education, taking into account the current academic scenario in which we observe that educational technology (Edtech) has a crucial role in both academic and administrative activities. The theoretical background takes place in the work of Pierre Moeglin (2016), named Industrialiser l'education: anthologie commentée (1913-2012). His work shows characteristics of the academic environment, institutionalized by the educational industries managers. The role played by 
Edtech also appears as an in important issue in the discussion: its place in the commercial sector, in terms of financial numbers, as well as its importance to distance education (EAD). In relation to teaching activities, educational institutions are adopting some information technology systems and apparatus in order to control actions and even behaviors of their teachers, besides control and evaluate their performance.

KeYwords: Edtech. Education Management. Industrialization of Education. Teaching Practice.

\section{Introdução}

Este artigo, na forma de ensaio teórico, analisa de forma crítica o processo de industrialização do ensino brasileiro. Uma das características para definiçáo das organizaçôes educacionais, a partir das últimas décadas do século XX, em decorrência desse processo de industrializaçáo - que não é uma particularidade brasileira -, tem sido a crescente influência do gerencialismo, já que as instituiçôes de ensino passaram a assumir modelos de gestấo voltados para a eficiência não só em termos de ensino, mas também em termos financeiros. (LIPMAN; HAINES, 2007).

No Brasil, autores como Oliveira (2009), Costa e Aquino (2012) e mem, a fonte de seu desenvolvimento moral e intelectual, o Cruz e Paula (2015) trataram da mercantilizaçáo do ensino criticando o processo de sua transformação em mercadoria, enquanto outros se preocuparam com sua financeirização, ou seja, com a formação de grandes oligopólios privados focados na maximização dos lucros, sendo que algumas dessas organizaçóes tornaram-se empresas de capital aberto com ações negociadas na Bolsa de Valores, Mercadorias e Futuros (BM\&F BOVESPA) - (COSTA, 2011; BITTAR; RUAS, 2012; BASTOS, 2013; ROMA, 2013, 2014; RUAS, 2014).

Essa tendência de busca crescente pela produtividade não é tão recente, cabendo observar que já em 1967, na introdução de sua obra intitulada L'industrie de l'enseignement (1967), na qual aplica a metodologia da análise econômica à educação, o economista Lê Thành Khôi $(1967$, p. 9) observava que:

Temos o hábito de tratar a educação como um direito do ho- 
instrumento de sua ascensão social, a condição da democracia política. Mas, o progresso das ciências e das técnicas, as exigências do crescimento e da pesquisa impóem também requerer da educação uma 'produtividade' máxima, respondendo às necessidades de nossa época.

Convém salientar aqui, a distinção estabelecida por Khôi entre educação e ensino. Para o autor, a educação é o conjunto de processos que preparam o homem para desempenhar seu papel na sociedade e compreende não só seu desenvolvimento intelectual, "[...] mas também sua formação física, moral e estética." (op.cit., p.13). Já o ensino consiste no processo de transmissão do conhecimento, com suas vicissitudes (KNIGHT, 2009). Embora reconheça que essa distinção seja muitas vezes de caráter formal e semântico, já que qualquer processo de ensino digno desse nome participa também da formação do espírito e do caráter, Khôi (1967, p. 13) observa que, "do ponto de vista da análise econômica, contudo, nós não podemos trabalhar senão com grandezas estatisticamente definidas, isto é, do ensino mais do que da educação."

Nesse contexto, no qual a presença da calculabilidade e do gerencialismo nas instituiçóes de ensino é crescente, o presente ensaio tem seu foco voltado para o impacto desse processo sobre o exercício da prática docente no cenário da educação superior. Seu objetivo principal é suscitar uma reflexão/discussão sobre o tema, levando em conta a presença da $e d u$ cational technology (Edtech) como componente do cotidiano acadêmicoadministrativo.

\section{Indicadores do processo de industrializaçáo}

Conforme defende Moeglin (2016, p. 9), o processo de industrialização da educação não é recente, embora seja ignorado pela maior parte dos especialistas: "Chega a ser intrigante sua surpresa quando eles descobrem que os termos industrialização e educação podem estar unidos e, mais surpreendente ainda, quando eles descobrem que a fórmula industrialização da educação ... aparece de fato há mais de cem anos [...]" Observa ainda esse autor que ainda maior seria o espanto desses especialistas ao saberem 
que o filósofo Emmanuel Kant, em seu trabalho Conflit des facultés, de 1798, preconizava um tratamento industrial (máxima eficiência em relação à produção e à transmissão do conhecimento) para o conjunto do saber (MOEGLIN, 2016, p. 10-11). Ressalva, no entanto - e é importante registrar a ressalva -, que essa eficiência máxima deveria obrigatoriamente vir acompanhada de uma máxima autonomia, pois para Kant o sábio não deve obedecer senão à razão e deve ser regido por uma norma interna e autônoma. (MOEGLIN, 2016, p. 11)

Diante da dificuldade de se estabelecer critérios precisos e seguros para caracterizar a industrialização da educação, Moeglin (2016) propóe a utilizaçáo de indicadores, observando que enquanto os critérios poderiam distinguir a priori o que é industrial daquilo que não é, os indicadores, por sua vez, só permitem verificar a posteriori em que medida uma determinada situação se aproxima ou se distancia do tipo industrial ideal (MOEGLIN, 2016, p. 54). Baseado em estudos anteriores, o autor propóe um padrão de análise para identificar traços de uma situação de industrialização da educação constituído por três indicadores, a saber: tecnologização, racionalização e ideologização, conceituados a seguir.

A tecnologização (technologisation) indica a presença e a utilização de dispositivos técnicos que acrescentam os usos que eles prescrevem e as práticas que eles modelam à dimensão material das ferramentas e médias que lhes são intrínsecas, ou seja, as normas e os padrões que eles comportam influenciam as formas de comunicação. Aliás, o próprio Moeglin (2010, p. 92) já alertou a respeito da constituição histórica das instituiçóes de ensino modernas, caracterizando-as como "uma burocracia a serviço de uma organização de massa." O autor exemplifica esse conceito referindo-se aos manuais escolares, observando que a função tecnológica desses dispositivos é a de "[...] fixar rotinas para maneiras de fazer, incorporadas e veiculadas mecanicamente sob a forma de habitus, não em uma perspectiva determinista, mas no sentido que Bourdieu dá aos seus "sistemas de disposição para a prática.” (MOEGLIN, 2016, p. 56) Nesse sentido, a tecnologização ressalta, além da instrumentação e midiatização desse habitus, seu registro e reprodução em maior ou menor escala. Conforme Peixoto e Araújo (2012), a visão contemporânea de tecnologia oscila entre a de uma ferramenta adaptável ao uso imputado pelo homem, e a que atribui a ela o poder de configurar a cultura e a sociedade. Destacam os autores 
que "tal dinâmica se reflete na apropriação da tecnologia pelo discurso e, consequentemente, pelas práticas pedagógicas.” (PEIXOTO; ARAÚJO, 2012, p. 255) Essa dualidade do que se conhece por Edtech (Educational Technology) é retratada mais adiante neste artigo.

No tocante à racionalização (rationalisation), Moeglin se refere ao racionalismo weberiano que, segundo ele, vai além da organização científica do trabalho (formalização, objetivação e codificação de tarefas, visibilidade e competências, prescrição, enquadramento e normatização de condutas, uso sistemático de procedimentos de controle etc.). $\mathrm{O}$ autor menciona também "a economia, pelo desenvolvimento do capitalismo, e o direito." (MOEGLIN, 2016, p. 58) Os pensadores mais antigos que se dedicaram ao assunto, continua o autor, enfatizam o papel determinante de critérios de rendimento e rentabilidade. Autores como J. F. Bobbitt, que em 1913 salientou a importância do papel desempenhado pelos diretores e inspetores na missão de zelar pela otimização dos meios, ou P. H. Combs, que se destaca no desenvolvimento de métodos técnicos e científicos que permitem avaliar e aperfeiçoar a performance do ensino em todos os níveis.

Contudo, o autor aponta que "[...] o taylorismo é apenas uma das características desta racionalizaçáo organizacional, a qual comporta também muitas outras formas." (MOEGLIN, 2016, p.58) O imperativo do produtivismo, continua o autor "[...] passa também por modos de organização pós-tayloristas e desburocratizados.” (op.cit., p.59) Nesse contexto, o autor cita, por exemplo, a autonomização, que consiste em estimular o estudante a estudar sozinho, ou eventualmente ajudado por pares (ou coach), com o objetivo de manter ou aumentar a eficiência produtiva. Observa ainda que essa inovaçấo tecnológica também objetiva que os estudantes interiorizem eles mesmos as normas de performance e de controle, fato este, continua o autor, facilmente observável nos cursos de educação a distância (op. cit., p.60), já que os sistemas de ferramentas técnico-pedagógicas são construídos com o objetivo de permitir a elaboração de cursos, manuais e documentos passíveis de armazenamento tecnológico, permanecendo disponíveis para acesso a qualquer tempo ou localização geográfica; (CLEGG, 1998; MOEGLIN, 2010)

Conforme pontua Moeglin (2016), essa racionalização exige que os atores envolvidos acreditem - ou sejam levados a acreditar - que, adotando os princípios da gestão racional, eles se comportam como atores racionais. 
Daí o surgimento do indicador chamado ideologização (ideologisation). A noção de ideologização designa o processo pelo qual "[...] adotando justificativas do tipo daquelas que lhes fornecem a religiáo do progresso e da modernidade, a crença na ordem irreversível da técnica e de outros argumentos semelhantes, os autores racionalizam a racionalidade de suas estratégias." (MOEGLIN, 2016, p. 60) Assim, a função da ideologia é a de ocultar as diferenças entre os atores, fazendo com que se associem e conjuguem seus esforços e passem a trabalhar juntos. Em tal contexto, "[...] fabricantes de material didático, gestores da educação, pedagogos e educadores abandonam as reticências que, de início impediam de trabalhar juntos na promoção de uma ferramenta, mídia ou dispositivo, tamanha era a divergência de seus interesses." (op.cit., p.61)

\section{Defensores e críticos da industrialização da educaçáo}

Ao analisar o trabalho publicado por J. F. Bobbit, publicado em 1913 sob o título de Some General Principles of Management Applied to the Problems of City - School Systems, Moeglin e Chaptal (2016) destacam que o autor propóe alinhar a educaçáo com os campos da produção e dos negócios, alegando que os modos industriais de gestão podem fornecer lições úteis para o campo da educação. Em suas palavras, "a educação é um processo de fabricação como o é o de uma usina que fabrica trilhos de aço: a personalidade do aluno deve ser produzida e moldada de acordo com o que se espera" (BOBBIT, 1913/2016, p. 82). Assim, a industrialização deve estar presente em partes iguais tanto na definição dos conteúdos a serem lecionados (úteis para a indústria) quanto nas maneiras de ensinar (pedagogias industriais). Além disto, as normas e objetivos do ensino devem ser fixados não pelos educadores, mas pelos representantes do mundo dos negócios. (MOEGLIN; CHAPTAL, 2016, p. 84)

De acordo com Thibault e Moeglin (2016), Joseph Wilbois preconiza, em sua obra La Nouvelle Éducation Française, publicada em 1922, liberar o estado de suas responsabilidades educativas e transferir para os sociólogos e psicólogos a responsabilidade de construir um novo sistema escolar. Seu projeto consiste em promover a gestão científica da produ- 
ção, pois, "De acordo com este ponto de vista, o sistema educativo parece com uma empresa que fabrica homens e mulheres, e a ciência, como nos outros setores de produção, é solicitada para aperfeiçoar o processo." (THIBAULT; MOEGLIN, 2016, p. 94). Segundo Wilbois (1922, p. 94): "em uma fábrica de homens, como em toda fábrica, se estuda: 1) o produto acabado que devemos entregar: aqui, o homem de amanhã [...]; 2) as qualidades da matéria prima a moldar: aqui, o aluno de hoje."

Segundo Ball, Debon e Moeglin (2016), além de suas intensas atividades no laboratório de psicologia de Harvard, Skinner também se dedicou a aperfeiçoar e comercializar suas próprias máquinas de ensinar: "a máquina, ela mesmo, naturalmente, não ensina. Ela é um instrumento que coloca o aluno em contato com o especialista que desenvolveu o material que ela apresenta. Ela permite realizar uma grande economia de trabalho, pois pode colocar um mesmo programador em contato com um número ilimitado de alunos." (BALL; DEBON; MOEGLIN, 2016, p. 105). Skinner também se tornou um dos defensores mais entusiasmados de uma abordagem industrial do sistema educativo, "[...] baseada em uma concepção materialista da sociedade e sobre os princípios do método experimental em educação em outros campos." (BALL; DEBON; MOEGLIN, 2016, p.104) Cabe observar ainda, continuam os autores, que na visão de Skinner as máquinas permitiriam aos educadores maior tempo de dedicação aos alunos, aumentando a eficiência, tal como nas propostas de Bobbitt e Wilbois; mas, ao contrário destes, sua proposta não busca "[...] a produção e a distribuição massiva de conteúdos padronizados para produzir aprendizes padronizados." (op.cit., p.108)

Barna e Moeglin (2016), ao comentarem a obra de Lê Thành Khôi já mencionada na introdução deste ensaio, observam que suas ideias não dâo grande importância às ferramentas e mídias educativas, concentrando-se na aplicação de uma abordagem industrial ao setor da educação, "[...] desenvolvendo formas de contabilização e apelando a um aparelho estatístico coerente e se baseando sobre regras confiáveis de cálculos de custos e rendimentos." (BARNA; MOEGLIN, 2016, p. 119) Por outro lado, preconiza a substituição dos mestres mais qualificados - portanto, os com maiores salários - por sistemas técnicos de difusáo em grande escala, com o objetivo de aumentar significativamente a produtividade do sistema educativo. Isso porque, em sua visão, esta é uma indústria intensiva em 
mão de obra, que tende sempre a aumentar esta intensidade pela redução da relação entre número de alunos/professor. (KHÔI, 1967, p. 14)

$\mathrm{Na}$ visão dos autores deste ensaio, é isso que assistimos hoje com os cursos de ensino a distância (EAD), que não mais se limitam aos cursos de graduação, mas também aos de pós-graduação. A dúvida que ainda fica é se essa modalidade de curso visa aumentar a produtividade do sistema, ou apenas a aumentar a receita financeira das instituiçóes de ensino envolvidas. Afinal, pelo que tem sido debatido até aqui, a premissa da lógica gerencial é de que tudo é calculável. Então, na perspectiva do Big Data, isso pode ser consequência do modelo MOOC (Massive Open Online Course). (MOEGLIN, 2016)

Por outro lado, adotando postura inversa, Harold A. Innis, economista e historiador canadense e especialista em comunicaçôes, considera que a industrialização da cultura, da informação e da educação, nivela por baixo. Conforme Tremblay e Paquelin (2016), Innis, que expôs suas ideias sobre educação principalmente em seu trabalho intitulado A Plea for Time, publicado em 1951, considera que transportar práticas da indústria para a educação, enxergando esta última como mercado que visa satisfazer o gosto dos alunos e os interesses dos professores, respectivamente percebidos como clientes e fornecedores, coloca a universidade em um mau caminho. "Em sua visão, a universidade é, antes de tudo, um lugar de formação do pensamento." (TREMBLAY; PAQUELIN, 2016, p. 132)

Também dentro de uma linha crítica ao processo de industrialização da educação, Moeglin e Petit (2016) identificam em Jacques Piveteau um defensor, na década de 1970, de uma nova educaçáo, propugnando a utilização de métodos ativos centrados nas pessoas e partidário fervoroso da educação continuada, sem esquecer que esses métodos requerem a aquisição, pelos alunos, de técnicas básicas de expressão e comunicação, redação de resumos etc. Em sua visão, o sistema escolar é uma instituição centralizada, "[...] como toda indústria, que para sobreviver tem a necessidade de se tornar gigantesca, se articular em cartéis, trustes, cada vez mais integrados." (PIVETEAU, 19732016, p. 142). Segundo os autores, Piveteau objetiva com a educação continuada "[...] uma forma de agir contra o imobilismo das posiçóes profissionais adquiridas de uma vez por todas graças ao diploma." (MOEGLIN; PETIT, 2016, p. 140). Embora reconheça, continuam os autores, a existência de um processo 
de industrialização da educação, salienta "[...] uma ligação forte e desastrosa entre autoritarismo e industrialismo" (op.cit., p.141). Ou seja, é preciso entender primeiro a escola como uma indústria antes de estabelecer uma estratégia realista para mudá-la, defendendo uma escola fora do sistema escolar por meio de uma educação permanente a vida toda (educação continuada).

Também alinhados com uma postura crítica, Metzger e Paquelin (2016) citam o economista francês Jean Gadrey. Ao analisarem suas ideias focadas na sociedade de serviços, os autores observam que elas ressaltam os perigos do neoliberalismo, salientando que suas pesquisas se concentram na elaboração de indicadores alternativos de riquezas. Com relação à tese da industrialização dos serviços, continuam os autores, Gadrey tem uma postura bastante crítica, afirmando que uma sociedade de serviços não pode funcionar integralmente como uma sociedade industrial. "Mais precisamente, o que ele procura analisar aqui é até que ponto certas atividades de serviços, realizadas por grupos profissionais ou profissôes organizadas, podem conhecer um crescimento de sua produtividade e uma padronização de seus métodos aplicando os princípios da industrialização.” (METZGER; PAQUELIN, 2016, p. 226)

Segundo Gadrey (1994), os membros de uma profissão (tal qual a de educador) se caracterizam pela "detenção de saberes especializados e formalizados, resultantes de uma formação superior que constituem a base dos serviços intelectuais que eles prestam e uma condição para o exercício da atividade pela qual ganham sua vida" (GADREY, 1994, p. 227). O autor ressalta ainda que os profissionais exercem uma parcela importante de suas atividades interagindo diretamente com seus clientes (no caso dos professores, seus alunos), os quais os procuram para a solução de problemas que exigem competências profissionais. Dessa forma, continua Gadrey (op.cit., p. 228-229) "se torna difícil padronizar a realidade dos problemas a serem resolvidos e as suas respectivas soluçōes".

Conforme se pode observar nos textos anteriormente comentados, um consenso a respeito dos eventuais benefícios sociais, e mesmo econômicos, do processo de industrialização da educação está longe de existir (Quadro 1). Todavia, a existência desse processo, ou ao menos a tentativa de implementá-lo, para o bem ou para o mal, é aceita até mesmo pelos seus críticos mais radicais. 


\begin{tabular}{|c|c|}
\hline Posição & Autor (argumento) \\
\hline \multirow{3}{*}{ Favorável } & $\begin{array}{c}\text { - Bobbit (Educação é fabricação: aluno pode ser moldado) } \\
\text { - Khôi (Aplicação de aparelho estatístico à educação) } \\
\text { - Skinner (Desenvolvimento de máquinas de ensino) } \\
\text { - Wilbois (O sistema educativo deve fabricar homens e mulheres) }\end{array}$ \\
\hline \multirow{3}{*}{ Contra } & $\begin{array}{c}\text { - Innis (A prática educacional não é prática de mercado) } \\
\text { - Gadrey (Os problemas do cotidiano educacional não são } \\
\text { padronizáveis) }\end{array}$ \\
& $\begin{array}{c}\text { - Piveteau (A posiçáo profissional não depende apenas do } \\
\text { diploma) }\end{array}$ \\
\hline
\end{tabular}

Quadro 1: Defensores e críticos da industrialização da educação Fonte: Elaborado pelos autores.

\section{Educação a Distância}

No caso da educação a distância (EAD), as características do processo de industrialização, mercantilização e financeirização são mais evidentes, uma vez que esse tipo de ensino requer investimentos elevados em pelo Technology, Education and Copyright Harmonization Act of 2002) e tutores especializados. Os recursos financeiros exigidos para tais investimentos são o que Moeglin (2010) classifica como o primeiro dentre três obstáculos que podem restringir o destacado crescimento que essa modalidade de ensino vem experimentando nos últimos anos.

O segundo obstáculo, ainda na visão do autor, se refere à inadequação dos conteúdos e à falta de coerência das políticas editoriais, mais especificamente "à defasagem entre os conceptores e os utilizadores e a multiplicação de discordâncias entre o que o dispositivo prescreve e o que o utilizador consegue fazer." (MOEGLIN, 2010, p. 74)

O último obstáculo, também conforme o que aponta Moeglin (2010), diz respeito à resistência de docentes, uma vez que a modalidade e-learning impóe situaçôes que lhes são desfavoráveis, como a insatisfação dos alunos no tocante à assimilação de conteúdos disponibilizados em plataformas de ensino. Tal panorama reflete as preocupaçóes de Jacquinot, 
pesquisadora internacional de renome recentemente falecida, relatadas na obra de Fichez e Moeglin (2016): o ensino não pode ignorar os fenômenos da tecnologização ligados à generalização do audiovisual e da multimídia, embora a modernidade tecnológica, por si, não possa assegurar avanço em termos de qualidade e inovação pedagógica. Assim, os autores registram a dificuldade de se conciliar duas necessidades aparentemente contraditórias: de um lado, a industrialização apoiada sobre a tecnologização educativa para atender (legítimas) exigências quantitativas de democratização do ensino; de outro, exigência qualitativa. Nesse sentido, Jacquinot (1993), reconhecendo a validade da industrialização do ensino, destaca a necessidade de se "articular a necessária tendência à industrialização com a racionalização da produção e suas consequências, além da urgente obrigação de aumentar, ao mesmo tempo, abrangência, qualidade e eficácia da formação, tanto inicial quanto contínua." (JACQUINOT, 1993, p. 82)

Outro grande entusiasta da EAD é Otto Peters, professor e pesquisador da Fern Universität in Hagen. De acordo com Barna, Guillemet e Moeglin (2016), Peters é frequentemente acusado de buscar, com o desenvolvimento de iniciativas de educação a distância, uma estratégia de economia de escala que reduza custos. Em resposta às críticas, segundo os autores, Peters (apud BARNA; GUILLEMET; MOEGLIN, 2016, p. 263) afirma que sempre defendeu a ideia de que "a industrialização deve ser entendida como uma resposta pedagógica a problemas pedagógicos, mas que sua análise requer também uma teoria global da educação, levando em conta fatores culturais, sociais e políticos que determinem seu modo de funcionamento." A tese de Peters, prosseguem os autores, defende que a educação a distância, a partir do final do século XX, rompeu radicalmente com os métodos de ensino presencial, encontrando abrigo no coração das indústrias educativas, que fizeram da EAD seu caminho para expansão de mercado.

\section{A questão da Educational Technology (EdTech)}

Embora também esteja presente nos cursos presenciais, é no campo da EAD, dos MOOCs e do e-learning que a educational technology (Edtech) predomina. Aliás, foi o desenvolvimento da Edtech que possibilitou o sur- 
gimento de novas formas de ensino/aprendizagem, constituindo um fenômeno que potencializou o processo de industrialização da educação.

$\mathrm{O}$ conceito de Edtech parece assumir múltiplas facetas. Para a elaboração deste artigo buscou-se, inicialmente, definição constante em três dicionários ingleses: Cambridge Dictionary - edtech: short for educational technology; education technology: the use of technology in education, or the design of such technology; Oxford Dictionary - edtech: short for educational technology; education technology: digital technology used to facilitate learning; e Collins Dictionary - edtech: short for educational technology; education technology: the use of technology, such as computers, within education, to aid the learning process. A busca revela, assim, que o termo diz respeito ao uso e à integração de dispositivos tecnológicos no campo da educação, em especial na escolar. Para apropriação conceitual do termo Edtech em âmbito acadêmico-científico, King, Rothberg, Dawson e Batmaz (2016) afirmam se tratar de "softwares, sistemas e aparatos utilizados para apoio ao 'negócio' no campo do ensino e da aprendizagem."

A expansão da Edtech é de tal ordem que em simples busca no Google, realizada pelos autores deste trabalho em 21 de junho de 2018, listou 5.470.000 resultados em menos de um segundo. Em linhas gerais, o que se obtém no tocante à definição do termo é que a EdTech se propóe a estabelecer conexão entre o modelo tradicional de educação com a experiência do mundo real, de modo a habilitar estudantes à atuaçáo numa economia que valoriza inovação e liderança, abrangendo, assim, grande parte da formação humana.

Edtech constitui hoje um segmento em forte expansão global no cenário das start-up's, ensejando inclusive a ediçâo de manuais para a implantação de empreendimentos nesse setor, a exemplo do e-book de livre acesso Passo a passo para criar uma edtech, disponibilizado no site www. inoveduc.com.br. Esse manual, em sua introdução, estima que existem atualmente no Brasil (novembro de 2017) cerca de 500 empresas dedicadas a essa atividade cujo mercado inclui a educação básica, a educação superior, o ensino de idiomas e o ensino corporativo nos segmentos de LMS (Learning Management System), ERP (Enterprise Resource Planning), CRM (Customer Relationship Management), aprendizagem cognitiva, aprendizagem adaptativa, cursos online, gestão da sala de aula, hardware, jogos educativos, tutoria, orientação vocacional, inteligência artificial, plataforma 
de vídeos, realidade virtual e aumentada etc. (PASSO A PASSO PARA CRIAR UMA EDTECH, 2017, p.5)

Em estudo que analisou o sistema educacional da Nova Zelândia, Wright e Peters (2017) destacam que um artigo publicado pela revista americana The Atlantic, em 2015, relata que o mercado de Edtech dos EUA totalizou US\$ 8,38 bilhóes no ano acadêmico de 2012-2013, contra US\$ 7,9 bilhóes no ano anterior, o que representou um crescimento de 11,7\% em relação a 2009. Salientam ainda os autores que, de acordo com a organização empresarial neozelandesa EDTechNZ, a tecnologia educacional é o setor que mais cresce em um mercado global de educação inteligente, estimado em US\$ 100 bilhôes, com previsão de crescer para US\$ 394 bilhóes até 2019. Ainda de acordo com os autores, a mesma fonte indica que a tecnologia educacional baseada 'na nuvem' vem apresentando um crescimento acelerado de $20 \%$ ao ano, com previsão de atingir US\$ 12 bilhôes até 2019 .

O processo de industrialização do ensino inclui ainda a comercialização das marcas das universidades, notadamente no setor de vestuário, papelaria, alimentação etc. Como exemplos, temos parcerias com empresas como Adidas, Calvin Klein, McDonald's, Tommy Hilfiger, Reebok e Starbucks, movimentando um mercado que passou de US\$2,5 bilhóes em 1995 para US\$ 4,3 bilhóes em 2010. (MIÈGE; MOEGLIN, 2016 p. 313) Wright e Peters (2017) relatam que a atual política educacional da Nova Zelândia incorpora uma variante contemporânea do discurso da sociedade da informação, baseada num "neoliberalismo amplamente utópico, enfatizando soluções universais e abstratas de 'techno-fix' para problemas educacionais, sociais e econômicos”. Os autores apontam ainda que tal discurso "enfatiza transformações técnicas da sociedade, destacando especialmente os benefícios comerciais, além de tratar as tecnologias digitais em geral como neutras e, por associação benigna, não necessitando de uma análise social ou política." (WRIGHT; PETERS, 2017, p.165) Os autores salientam que, cada vez mais, a indústria de tecnologia educacional intervém diretamente na educação, pois " o mercado baseado no imperativo da venda se tornou uma lógica motriz para as tecnologias digitais nas escolas, enquanto a aprendizagem se perde na pressa para as empresas lucrarem com as escolas." (op.cit., p.164) 
Com relação à percepção dos discentes, Jayaratne e Moore (2017), com base nos resultados de uma pesquisa realizada com alunos do College of Agriculture and Life Sciences, da North Carolina State University, constataram que a percentagem de alunos que preferem aulas online é muito baixa, mas que cerca de $1 / 4$ dos alunos pesquisados eventualmente as assistiriam se tivessem tal opção na forma híbrida (ora online, ora presencialmente), de acordo com suas conveniências e decisão baseada na flexibilidade de horário. Os resultados desse estudo indicaram também que vídeos instrutivos, material elaborada em power point, questionários, gravação de aula em vídeo, áudios instrucionais, estudos de caso, materiais de leitura e projetos práticos foram atividades de ensino valorizadas pelos alunos.

No contexto brasileiro, pesquisa realizada por Souza, Franco e Costa (2016) com discentes dos cursos de licenciatura em Física e em Pedagogia da Universidade Estadual de Maringá revela que os discentes apontam como aspectos positivos da EAD a facilidade de acesso ao ensino superior e a adequação da modalidade às suas condições de vida. Os resultados revelam ainda a preferência dos estudantes pelo livro impresso e pelas videoaulas como suportes à aprendizagem; como aspecto negativo, apontam a presença de fragilidades no processo de comunicação entre tutores e alunos.

Em relação a autores brasileiros que registram críticas à $\mathrm{EAD}$, temos os já mencionados trabalhos de Costa e Aquino (2012) e Cruz e Paula (2015). O primeiro deles destaca que "concorre para a política nacional de EAD institucionalizar o ensino industrializado no país, em meio ao movimento da política educacional brasileira de impor ao sistema de ensino, como um todo, um processo de mercantilização e racionalização sem precedentes." (COSTA; AQUINO, 2012, p. 41). Cruz e Paula (2015) salientam que a implementação de políticas neoliberais na década de 90 criou um panorama que expôs a educação nacional a um intenso processo de desnacionalização, sendo a EAD um de seus principais vetores.

Nesse sentido, embora os autores deste ensaio adotem uma postura crítica em relação à política nacional de EAD, é mister reconhecer aspectos como a viabilização do acesso ao ensino para atores até então excluídos do sistema, seja por motivos financeiros ou por aspectos de ordem logística (distância em relação aos centros de ensino ou falta de flexibilização no tocante aos horários dos cursos). 


\section{Notas sobre o processo de industrializaçáo da educaçáo no contexto brasileiro}

A tecnologização (technologisation) é constatada no contexto brasileiro não apenas nos instrumentos de gestão e controle das atividades docente e discente (sistemas informáticos de apoio pedagógico e gestão acadêmica, usados pelos docentes/discentes, que podem ser acessados não só por aqueles diretamente envolvidos, mas também pelos gestores da instituição), mas também nos dispositivos utilizados para o desenvolvimento de pesquisas (bases de dados, programas informáticos e ferramentas tecnológicas para análises matemáticas, estatísticas, de conteúdo etc.). Esses dispositivos, se por um lado facilitam o trabalho do docente, por outro o direcionam, ou ao menos o limitam. Debate mais específico a esse respeito pode ser constatado na abordagem da Actor-Network Theory (ANT), desenvolvida, entre outros, por Callon (1986), Law (1986), Latour e Wolgar (1986) e Latour (1987 e 1988).

Os indicadores de racionalização (rationalisation) também estão fortemente presentes no contexto nacional. Os cursos de graduação são ranqueados por meio de indicadores de eficiência calculados pelo Instituto Nacional de Estudos e Pesquisas Educacionais (INEP) com base nos resultados obtidos pelos discentes no Exame Nacional de Desempenho dos Estudantes (ENADE). A preocupação em obter uma boa classificação nesse ranking é tão intensa que chega a fomentar comportamentos disfuncionais em algumas instituiçóes que se utilizam de artifícios para só inscrever no exame alunos nos quais vislumbram possibilidades de que obtenham um bom desempenho.

Nos cursos de pós-graduação (strictu sensu), a Coordenação de Aperfeiçoamento de Pessoal de Nível Superior (CAPES) adota critérios de eficiência, próprios da atividade empresarial, não só para avaliar o desempenho desses cursos, mas também para ranqueá-los. Esse ranqueamento tem consequências diretas não só para os cursos em questão, mas também, e principalmente, para a carreira profissional dos docentes envolvidos, uma vez que estão baseados quase que exclusivamente em calculabilidade (MOEGLIN, 2010). São utilizados e mesmo potencializados pelas instituiçóes para definir políticas de credenciamento e descredenciamento de docentes e de progressão na carreira, cenário que gera também disputas e 
dissensos entre instituiçôes, programas e pesquisadores, conforme apontaram Magalhães e Real (2018). Além disso, dispositivos característicos de organizações pós-tayloristas como a autonomização (estímulo para o estudante estudar sozinho) estão presentes e são estimulados não só com objetivos pedagógicos, mas também como forma de aumentar a eficiência financeira do sistema.

Com relação à ideologização (ideologisation), sua presença pode ser observada não só no nível do discurso, mas também na prática acadêmica. No nível do discurso, as evidências podem ser constatadas até mesmo na utilização de uma linguagem própria dos profissionais da área de marketing empresarial para nomear os cursos e as disciplinas, com uma preocupação óbvia de atrair clientes. No âmbito da atividade acadêmica, pouco espaço é reservado para uma discussáo crítica das práticas e teorias consagradas de administração vinculadas ao status quo: eficiência, maximização de lucros, avaliação de desempenho, racionalidade etc.

Tais questôes decorrem das críticas constantes em relação à falta de relevância da pesquisa acadêmica para a prática profissional. A esse respeito, vale a leitura de trabalhos como os de Hopwood (1983), Scapens (2006), Ahrens e Chapman (2007), Malmi e Granlund (2009), Malmi (2010) e Scapens (2010).

\section{Impactos no exercício da atividade docente}

Com relação à prática da docência, os impactos do processo de industrialização da educação são consideráveis. Baseado na lógica de mercado, esse processo exige das instituiçóes de ensino, sejam elas públicas ou privadas, modelos de gestão baseados na calculabilidade e na busca pela eficiência, ou seja, como defende Lipman e Haines (2007 p. 489), modelos gerencialistas caracterizados por relaçóes de quase mercado, o que implica práticas pautadas no desempenho do docente e, implicitamente, na sua vigilância e controle (BALL, 2009, p. 25).

É nesse contexto que dispositivos de vigilância, controle e adestramento (dressage) da prática docente são introduzidos no ambiente educacional por esses modelos gerencialistas, particularmente pelos sistemas de informação disponibilizados pela Edtech (MENDONÇA NETO; 
ANTUNES; VIEIRA, 2015, p. 667). Esses sistemas, quando analisados sob a ótica de Foucault (1975, p. 200-227), ao mesmo tempo em que facilitam algumas das atividades dos docentes, servem também para vigiar, adestrar, controlar e avaliar suas atividades e seu desempenho, via critérios de calculabilidade, tais como número de acessos, tempo de permanência online, número de tarefas solicitadas aos alunos etc.

Além disso, em função de seu próprio desenho, esses sistemas induzem à padronização da prática pedagógica, de forma a facilitar a substituição do docente. Incluem também plataformas de suporte administrativo que transferem para o docente atividades administrativas sem nenhum caráter pedagógico, mas que passam a fazer parte de suas obrigaçóes, ausente qualquer remuneração adicional. Obedecem, assim, a uma lógica de redução de custos característica dos sistemas gerencialistas.

Soma-se a esse contexto a precarização financeira da atividade docente, que é ainda mais grave nos cursos de EAD, haja vista, por exemplo, a cessão compulsória de direitos autorais sobre material produzido, além do direito de imagem, que são componentes remunerados de forma muitas vezes irrisória, passando a ser de propriedade da instituição de ensino para utilização posterior.

Essa conjunção de um sistema gerencialista pautado na calculabilidade do desempenho docente, aliada à precarização financeira da atividade pedagógica, tem suscitado práticas de resistência materializadas em desvios de comportamento (misbehavior) na gestão das instituiçóes de ensino, conforme relatam Vieira, Mendonça Neto e Antunes (2015).

\section{Consideraçóes Finais}

A mercantilização dos saberes, consequência da tendência à industrialização e responsável pela crise de valores tradicionais da educação (serviço público a serviço do saber crítico) não deve nos obrigar a reduzir a definição de educandos à dimensão única funcional de futuros agentes econômicos. Mesmo esse objetivo produtivo exige indivíduos socialmente integrados, conscientes de suas possibilidades, movidos pelo desejo de saber e aprender constantemente, e o advento da Edtech deve ser assumido como propulsor de tal postura. Assim, considerar iniciativas próprias 
da Edtech no ambiente educacional brasileiro exige cuidado como tempo apropriado para elaboração de projetos, implementação de processos e desenvolvimento de produtos. Açóes de curto prazo, como alertam King, Rothberg, Dawson e Batmaz (2016), tendem a fracassar em termos de ensino e de aprendizagem.

Por outro lado, também observado neste artigo, os sistemas voltados à gestão educacional atuam como parte dos dispositivos de controle, vigilância e dressage da atividade docente, pois, além dos módulos de apoio pedagógico, ocultam uma prática de vigilância e controle institucional que restringe a iniciativa e a liberdade na prática cotidiana de quem ensina. Conforme relatam Peixoto e Araújo (2012, p. 264), "as tecnologias são construtos sociais, ou seja, não podem ser vistas apenas como o fruto lógico de um esquema de desenvolvimento do progresso técnico, pois são resultantes de orientaçóes estratégicas, de escolhas deliberadas, num determinado momento dado da história, e em contextos particulares."

Outro alerta, a título de proposta para reflexôes e trabalhos futuros, diz respeito à atuação (e atração) de personagens alheios ao cenário da educação: investidores e negociantes com origem no mercado financeiro convencional têm, cada vez mais, assumido controle de instituiçôes de ensino, na perspectiva de lucro e aumento de patrimônio. Como resultado, constata-se o surgimento de um 'estilo gerencial' na gestão da educação que se caracteriza pelo enxugamento de estrutura (curricular, inclusive) e pela relativização da importância da titulação acadêmica. $\mathrm{O}$ domínio de aparatos tecnológicos, por sua vez, passa a ser competência indispensável ao docente dos tempos atuais. Assim, voltamos à provocação de Moeglin (2016), que, ao contextualizar seus indicadores no processo de industrialização na educação brasileira, indaga: Qual o output desta indústria? O que ela entrega para a sociedade? Mais especificamente, quais os benefícios que seus cursos trazem para a sociedade?

\section{Referências}

AHRENS, T.; CHAPMAN, C. S. Management accounting as practice. Accounting, Organizations and Society, 32, 1-27, 2007. 
BALL, J. M.; DEBON, C.; MOEGLIN, P. Burrhus F. Skinner: Le précepteur mécanique. In: MOEGLIN, P. (ed.). Industrialiser l'education: anthologie commentée (1913-2012). Vincennes: Presses Universitaires de Vincennes, 2016.

BALL, S. J. The education debate. Bristol: The Policy Press, 2009.

BARNA, J.; MOEGLIN, P. Lê Thành Khôi: Productivité éducative et progress social. In: MOEGLIN, P. (ed.). Industrialiser l'education: anthologie commentée (1913-2012). Vincennes: Presses Universitaires de Vincennes, 2016.

BASTOS, P. P. Z. Financeirização, crise, educação: considerações preliminares. Texto para Discussão. IE/UNICAMP, Campinas, 217, 1-22, 2013.

BARNA, J.; GUILLEMET, P.; MOEGLIN, P. Otto Peters, les revoluttions industrielle de l' ensseignement à distance. In: MOEGLIN, P. (ed.). Industrialiser l'education: anthologie commentée (1913-2012). Vincennes: Presses Universitaires de Vincennes, 2016.

BITTAR, M.; RUAS, C. M. S. Expansão da Educação Superior no Brasil e a formação dos oligopólios - hegemonia do privado mercantil. EccoS - Revista Científica, 29, 115-133, 2012.

BOBBIT, J. F. Some general principles of management applied to the problems of city-school systems. In: MOEGLIN, P. (ed.). Industrialiser l'education: anthologie commentée (1913-2012). Vincennes: Presses Universitaires de Vincennes, 2016.

CALLON, M. Some elements of sociology of translation: domestication of the scallops and the fishermen of St Brieux Bay. In: LAW, J. (ed.) Power, action, and belief: A new sociology of knowledge? London: Routledge \& Kegan Paul Books Ltd., 1986.

CLEGG, S. Foucault, power and organizations. In: MCKINLAY, A.; STARKEY, K. (ed.). Foucault management and organization theory. London: Sage Publications Ltd., 1998.

COSTA, F. L. O. A mercantilização da educação no Brasil sob a lógica da especulaçáo financeira. Fineduca - Revista de Financiamento da Educação, Porto Alegre, 1 (7), 1-16, 2011.

COSTA, A. R. F.; AQUINO, M. A. Industrialização do ensino e política de educação a distância. Ciência em Movimento, XIII (26), 41-51, 2012.

CRUZ, A. G.; PAULA, M. F. C. O setor privado-mercantil de educação superior no Brasil e a educação a distância. Germinal: Marxismo e Educação em Debate, Salvador, 7 (2), 242-251, 2015.

EDTECH. CAMBRIDGE DICTIONARY. Disponível em https://dictionary. cambridge.org/pt/ dicionario/ingles-portugues/. Acesso em 21/04/2018

EDTECH. Collins dictionary. Disponível em https://www.collinsdictionary.com/pt/ dictionary/english Acesso em 21/04/2018. 
EDTECH. Oxford dictionary. Disponível em https://en.oxforddictionaries.com/. Acesso em 21/04/2018

FICHEZ, E.; MOEGLIN, P. Penser la dimension industrielle de la Technologisation. In: MOEGLIN, P. (ed.) Industrialiser l'education: anthologie commentée (1913-2012). Vincennes: Presses Universitaires de Vincennes, 2016.

FOUCAULT, M. Surveiller et punir. Paris: Éditions Gallimard, 1975.

GADREY, J. Les relations de service et d'analyse du travail des agents. Sociologie $d u$ travail, 3, 381-389, 1994.

HOPWOOD, A. G. On trying to study accounting in the contexts in which it operates. Accounting, Organizations and Society, 8, 287-305, 1983.

JACQUINOT, G. La communication éducative médiatisée: de l'âge de pierre à l'âge de bronze. Études de communication, 14, 77-90, 1993.

JAYARATNE, K.S.U.; MOORE, G. Perceptions of college students toward online classes: implications for teaching online. NACTA Journal, 61(4), 304 - 309, 2017.

KHÔI, L. T. L' industrie de l'enseignement. Paris: Les Éditions de Minuit, 1967.

KING, M. R. N.; ROTHBERG, S. J.; DAWSON, R. J.; BATMAZ, F. Bridging the edtech evidence gap: a realist evaluation framework refined for complex technology initiatives. Journal of Systems and Information Technology, 18 (1), 18-40, 2016.

KNIGHT, J. What can we do about teacher resistance? Phi Delta Kappan, 90 (7), 508-513, 2009.

LATOUR, B.; WOOLGAR, S. Laboratory life: the construction of scientific facts. 2nd. ed. Princeton: Princeton University Press, 1986.

LATOUR, B. Science in Action: how to follow scientists and engineers through society. Cambridge: Harvard University Press, 1987.

LATOUR, B. The Pasteurization of France. Cambridge, Harvard University Press, 1988.

LAW, J. On the methods of long-distance control: vessels, navigation, and the Portuguese route to India. In: LAW, J. (ed.) Power, action, and belief: a new sociology of knowledge? London: Routledge \& Kegan Paul Books Ltd., 1986.

LIPMAN, P.; HAINES, N. From Accountability to Privatization and African American Exclusion. Education Policy, 21(3), 471-502, 2007.

MAGALHÁES, A. M. S.; REAL, G. C. M. Situando os debates sobre a avaliação da pós-graduação: os estudos do campo pelo campo. EccoS - Revista Científica, São Paulo, n. 46, p. 131-148, 2018.

MALMI, T. Reflections on paradigms in action in accounting research. Management Accounting Research, 21, 121-123, 2010. 
MALMI, T.; GRANLUND, M. In search of management accounting theory. The European Accounting Review, 18, 597-620, 2009.

MENDONÇA NETO, O. R.; ANTUNES, M. T. P.; VIEIRA, A. M. Controle do trabalho docente: provocaçóes foucaultianas para análise da gestáo universitária. Avaliação, 20 (3), 665-683, 2015.

METZGER, J. L.; PAQUELIN, D. Jean Gadrey: contradiction dans les termes? In: MIÈGE, B.; MOEGLIN, P. Bjorn Stensaker. Politique de marques. In: MOEGLIN, P. (ed.). Industrialiser l'education: anthologie commentée (1913-2012). Vincennes: Presses Universitaires de Vincennes, 2016.

MOEGLIN, P. (ed.) Industrialiser l'education: anthologie commentée (1913-2012). Vincennes: Presses Universitaires de Vincennes, 2016.

MOEGLIN, P. Les industries éducatives. Paris: Presses Universitaires de France, 2010.

MOEGLIN, P. Introduction. In: MOEGLIN, P. (ed.) Industrialiser l'education: anthologie commentée (1913-2012). Vincennes: Presses Universitaires de Vincennes, 2016.

MOEGLIN, P.; CHAPTAL, A. John Franklin Bobbit - Taylor à l'école. In: MOEGLIN, P. (ed.). Industrialiser l'education: anthologie commentée (1913-2012). Vincennes: Presses Universitaires de Vincennes, 2016.

MOEGLIN, P.; PETIT, L. Jacque Piveteau, comme la prodution industrielle, le système scolaire? In: MOEGLIN, P. (Ed.). Industrialiser l'education: anthologie commentée (1913-2012). Vincennes: Presses Universitaires de Vincennes, 2016.

OLIVEIRA, R. P. A transformação da educação em mercadoria no Brasil. Educação e Sociedade, Campinas, 30 (108),739-760, 2009.

PASSO A PASSO PARA CRIAR UMA EDTECH (2017). Disponível em < http:// pages.folhadirigida.com.br/ebook-como-criar-uma-edtech-inoveduc $>$. Acesso em: 21 abr. 2018.

PEIXOTO, J.; ARAÚJO, C. H. S. Tecnologia e educação: algumas consideraçóes sobre o discurso pedagógico contemporâneo Educação \& Sociedade, 33(118), 253-268, 2012.

PIVETEAU, J. École et industrie. In: MOEGLIN, P. (ed.). Industrialiser l'education: anthologie commentée (1913-2012). Vincennes: Presses Universitaires de Vincennes, 2016.

ROMA, C. C. L. Financeirização da Política Educacional em Tempos de Neoliberalismo. VI Jornada Internacional de Politicas Públicas. São Luiz, Universidade Federal do Maranhão, Brasil, 2013.

ROMA, C. C. L. A Financeirização da Educação Superior Brasileira e Seus Rebatimentos para uma Universidade Socialmente Responsável. Congreso Universidad, III (1), 1-8, 2014. 
RUAS, C. M. S. Educação superior privada mercantil e seus oligopólios: a megafusão Anhanguera e Kroton. Anais do XII Encontro de Pesquisa em Educação Centro-Oeste: Pós-graduação e pesquisa em educação: contradiçóes e desafios para a transformação social. Goiânia: PUC-GO-13, 2014.

SCAPENS, R. W. Practice, theory and paradigms. Management Accounting Research, 21, 77-78, 2010.

SCAPENS, R. W. Understanding management accounting practices: a personal journey. The British Accounting Review, 38, 1-30, 2006.

SOUZA, S.; FRANCO, V. S.; COSTA, M. L. F. Educação a distância na ótica discente. Educação e Pesquisa, 42 (1), 99-113, 2016.

THIBAULT, F.; MOEGLIN, P. Joseph Wilbois: Mysticisme social et science de l'education. In: MOEGLIN, P. (Ed.) Industrialiser l'education: anthologie commentée (1913-2012). Vincennes: Presses Universitaires de Vincennes, 2016.

TREMBLAY, G.; PAQUELIN, D. Harold A. Innis: um doyen contre les derives de l'industrialisation. In: MOEGLIN, P. (Ed.). Industrialiser l'education: anthologie commentée (1913-2012). Vincennes: Presses Universitaires de Vincennes, 2016.

VIEIRA, A. M.; MENDONÇA NETO, O. R.; ANTUNES, M. T. P. Aspectos da resistência na atividade docente. Educação e Pesquisa. 41(3), p. 743-757, 2015.

WILBOIS, J. La Nouvelle Éducation Française. In: MOEGLIN, P. (Ed.) Industrialiser l'education: anthologie commentée (1913-2012). Vincennes: Presses Universitaires de Vincennes, 2016.

WRIGHT, N.; PETERS, M. Sell, sell, sell or learn, learn, learn? The EdTech market in New Zealand's education system - privatization by stealth? Open Review of Educational Research, 4(1), 164-176, 2017.

Recebido em 9 out. 2018 / Aprovado em I2 nov. 2018

\section{Para referenciar este texto:}

NETO, O. R. M.; VIEIRA, A. M.; ANTUNES, M. T. P. Industrialização da educação, Edtech e prática docente. EccoS - Revista Científica, São Paulo, n. 47, p. 149-170. set/dez. 2018. Disponível em: <https://doi.org/10.5585/EccoS.n47.10702>. 